\title{
Degradación enzimática de celulosa por actinomicetos termófilos: aislamiento, caracterización y determinación de la actividad celulolítica
}

\section{Enzymatic degradation of cellulose for thermophilic actinomycete: isolation, characterization and cellulolytic activity determination}

\author{
Pablo Ramírez y Juana María Coha *
}

Presentado: $10 / 04 / 2003$

Aceptado: 26/05/2003

\section{Resumen}

Se aislaron 145 cepas de actinomicetos celulolíticos termófilos a partir de 71 muestras de compost, suelos, estiércol y heno de nuestro medio. Las especies de actinomicetos que más prevalencia tuvieron en las muestras estudiadas fueron Streptomyces sp. (50,63\%), Thermomonospora curvata $(15,82 \%), T$. chromogena $(13,92 \%)$, seguida de otras especies en menor proporción. Se evaluó la actividad endoglucanasa, exoglucanasa y $\beta$-glucosidasa de 10 cepas de actinomicetos celulolíticos. Entre éstas la cepa de Streptomyces sp. 7CMC10 mostró los mayores niveles de actividad correspondientes a 20,14; 2,61 y 5,40 Ul/mg de proteína, respectivamente.

Palabras clave: Actinomicetos, celulasas, termófilos, Streptomyces, Thermomonospora, biotecnología.

\begin{abstract}
One hundred and forty five cellulolytic thermophilic actinomycete strains were isolated from 71 compost, soil, hay and dung samples. Streptomyces sp. (50,63\%), Thermomonospora curvata $(15,82 \%)$, T. chromogena $(13,92 \%)$, and other species were identified. Endoglucanase, exoglucanase and $\beta$-glucosidase activities were evaluated from 10 cellulolytic actinomycete strains. Among these the Streptomyces sp. 7CMC10 strain showed the biggest activity levels corresponding to 20,$14 ; 2,61$ and $5,40 \mathrm{UI} / \mathrm{mg}$ of protein, respectively.
\end{abstract}

Keywords: Actinomycetes, cellulases, thermophilic, Streptomyces, Thermomonospora, biotechnology

\section{Introducción}

La celulosa es uno de los componentes más abundantes de la biomasa vegetal que es degradada por una serie de microorganismos mediante la acción de varias enzimas no asociadas en complejos, como en los hongos filamentosos y en algunos actinomicetos o formando un complejo denominado "celulosoma", como en los clostridios y en bacterias del rumen (Murashima et al., 2002; Lynd et al., 2002). Estas enzimas han sido ampliamente estudiadas en hongos mesófilos, tales como Trichoderma reesei (Lynd et al., 2002). Sin

*Laboratorio de Microbiología Molecular, Facultad de Ciencias Biológicas, Universidad Nacional Mayor de San Marcos,

embargo, sus actividades hidrolíticas son afectadas por una serie de factores físicos y químicos que limitan su aplicación a nivel industrial. Por ello, existe la necesidad de aislar cepas con mejores rendimientos en la cantidad de enzimas liberadas al medio extracelular y que mantengan la calidad intrínseca de dichas enzimas, además que expresen una elevada estabilidad de su actividad a $\mathrm{pH}$ extremos, solventes orgánicos, detergentes iónicos y principalmente la de mantener sus actividades enzimáticas a elevadas temperaturas de reacción. Por esta razón, los microorganismos termófilos han sido sugeridos como fuentes alternativas de celulasas por la termoestabilidad de sus enzimas, propiedad ventajosa en aplica-

eMail Pablo Ramírez: pramirezr@unmsm.edu.pe 
ciones industriales (Zeikuz et al., 1981). Entre las bacterias que destacan tenemos algunas especies de los géneros Clostridium, Streptomyces, Thermomonospora y Thermobifida (exThermomonospora) (Walter y Schrempf, 1996). En el caso de los clostridios, Clostridium cellulovorans (Murashima et al., 2002) hidroliza la celulasa en condiciones anaeróbicas; en tanto que las especies celulolíticas de Streptomyces, Thermomonospora y Thermobifida la degradan en un ambiente aeróbico. Taxonómicamente los géneros Streptomyces, Thermomonospora y Thermobifida se ubican en el Orden Actinomicetales y son comúnmente denominados actinomicetos.

En el Perú no hay estudios sobre la flora actinomicetal que participe en la degradación de la celulosa. Por este motivo, en la presente investigación nos planteamos aislar y caracterizar actinomicetos celulolíticos termófilos aislados de nuestro medio que posean un alto rendimiento de celulasas. Con esta finalidad se analizaron muestras de compost, suelos, estiércol y heno; seleccionandose cualitativamente las 10 mejores cepas productoras de celulasas y a éstas se les determinaron cuantitativamente la actividad endoglucanasa, exoglucanasa y $\beta$ glucosidasa.

\section{Materiales y métodos}

\section{Recolección de las muestras.}

Se procesaron 71 muestras entre compost (54,93\%), suelos (25,35\%), estiércol (12,68\%) $\mathrm{y}$ heno $(7,04 \%)$ (Tabla 1), procedentes de Cieneguilla (14,68\%), Apurímac (9,86\%), Cañete (7,04\%), La Molina-UNA (29,58\%), Hipódromo de Monterrico (7,04\%), Instituto Bircher Benner $(5,64 \%)$ y preparados en el laboratorio $(26,76 \%)$.

Las muestras de suelos fueron colectadas a una profundidad de $2 \mathrm{~cm}$ y en cantidad de $20 \mathrm{~g}$ por muestra. Las muestras de estiércol y heno fueron tomadas utilizando pinzas estériles en una cantidad de $30 \mathrm{~g}$, aproximadamente. En el caso de compost, se obtuvieron muestras de dos tipos: una colectada en la Univer- sidad Nacional Agraria (UNA) y en el Instituto Bircher Benner (Lima), preparada de acuerdo a los métodos tradicionales. El muestreo se realizó utilizando bolsas de polietileno (Nasco Whirl-Pak) en una cantidad de $30 \mathrm{~g}$. El otro tipo de compost fue preparado in vitro siguiendo las recomendaciones de Cross (1981) y de Morales y Masson (1988).

\section{Aislamiento Primario.}

Se tomó un gramo por muestra y se realizaron diluciones seriadas hasta $10^{-12}$ en solución salina y se sembraron mediante diseminación con espátula de Drigalski en el medio de cultivo propuesto por Stutzenberger et al. (1970) y en el Agar Czapek-Dox (Difco) modificado cambiando la sacarosa por celulosa microcristalina (Merck) o carboximetilcelulosa (CMC, Sigma) al 1\% y añadiéndole nistatin (Squibb) $50 \mu \mathrm{g} / \mathrm{ml}$ de medio. Los cultivos fueron incubados a 50 ${ }^{\circ} \mathrm{C}$ durante 7 días. Se comprobó la pureza de las cepas aisladas mediante resiembras en Agar Czapek-Dox modificado y en Agar Czapek-Dox Extracto de Levadura Casaminoácidos (CYC) según Cross (1981).

\section{Identificación de las cepas aisladas.}

Se identificaron según Crawford (1975), Cross (1981), McCarthy y Cross (1984a y 1984b) y Cross (1989). Esta consistió en estudios macroscópicos y microscópicos de las colonias y en pruebas bioquímicas y fisiológicas. Los estudios macroscópicos consistieron en evaluar el tipo de micelio aéreo, tipo de micelio vegetativo, color de micelio vegetativo y del micelio aéreo, producción de pigmentos difusibles en el medio de cultivo y consistencia de las colonias. Todas estas observaciones se realizaron en Agar CYC. Los estudios microscópicos consistieron en evaluar el tipo y disposición de las esporas, con el fin de separar los estreptomicetos de los actinomicetos monospóricos (Cross, 1981; McCarthy y Cross, 1984a, 1984b; Cross, 1989); para ello se realizaron microcultivos con laminillas inclinadas en un ángulo de $45^{\circ}$ en Agar CYC y las cepas se sembraron en el área más próxima a la la- 
minilla, éstas se incubaron a $45^{\circ} \mathrm{C}$ durante 5 días. Cumplido el tiempo de incubación, se extrajeron las laminillas y se realizó el montaje con azul de lactofenol para su observación microscópica.

Los actinomicetos monospóricos identificados mediante los estudios macroscópicos y microscópicos se sometieron a pruebas bioquímicas y fisiológicas, tales como la prueba de la oxidasa (dicloruro de tetrametil $p$ fenilendiamina al 1\%, Sigma), utilización de la sacarosa y la lactosa, hidrólisis del almidón, degradación de la celulosa microcristalina y CMC al $1 \%$, crecimiento en las condiciones siguientes: a pH 11,0 , a $53{ }^{\circ} \mathrm{C}$, desarrollo en cloruro de tetrazolio (Merck) al 0.002\% (p/v) y en cristal violeta al $0,00002 \%$ (p/v) (Sigma), de acuerdo a Cross (1981), McCarthy y Cross (1984a y 1984b).

\section{Determinación cualitativa de la activi- dad celulolítica.}

Las cepas aisladas fueron evaluadas en su capacidad celulolítica, según su crecimiento en dos medios mínimos líquidos cuya única fuente de carbono fueron tiras de papel filtro: el medio de Crawford y McCoy (1972), en el cual se cambió la CMC por tiras de papel filtro (Whatman N. ${ }^{\circ}$ 1) y el medio de Skinner (1960), al que se le añadió extracto de levadura $(0.01 \%)$ y tiras de papel filtro (Whatman N. $\left.{ }^{\circ} 1\right)$. Los cultivos se incubaron a $45^{\circ} \mathrm{C}$ en el caso del género Streptomyces, y a $50^{\circ} \mathrm{C}$ si se trataba del género Thermomonospora hasta los 5 días; y se examinaron diariamente para evaluar la capacidad degradativa sobre el papel filtro (Ramasamy, 1981).

Las cepas se agruparon de acuerdo al siguiente criterio de actividad celulolítica:

$\begin{array}{lc}\text { Muy buena } & 4+ \\ \text { Buena actividad } & 3+ \\ \text { Regular actividad: } & 2+ \\ \text { Escasa actividad: } & 1+ \\ \text { Ausencia de actividad: - }\end{array}$

\section{Determinación cuantitativa de la acti- vidad celulolítica.}

De las cepas que presentaron elevadas actividades según los criterios establecidos anteriormente, se seleccionaron 10 para las determinaciones cuantitativas de las celulasas. Con este fin, se inocularon $40 \times 10^{6}$ esporas por $100 \mathrm{ml}$ de medio mínimo de Crawford y McCoy (1972) más CMC y lactosa al 1\% como inductores y Tween 80 (Sigma) 0,2\%. Las cepas fueron incubadas en baño maría con agitación constante a $45{ }^{\circ} \mathrm{C}$ en el caso del género Streptomyces y a $50{ }^{\circ} \mathrm{C}$ en el caso del género Thermomonospora. A las $72 \mathrm{~h}$ se extrajeron muestras para las determinaciones de las actividades enzimáticas de las celulasas, de proteínas solubles y de biomasa celular.

\subsection{Actividad endo- $\beta$-1,4-Glucanasa (EC} 3.2.1.4) o CMCasa. La actividad de la enzima endoglucanasa de los actinomicetos fue determinada siguiendo las recomendaciones de Stutzenberger (1972); se utilizaron líquidos postcultivos libres de células, obtenidos por centrifugación $(6000 \times \mathrm{g}$ por $30 \mathrm{~min})$ y filtración a través de una membrana de celulosa (Millipore HA, 0,22 mm). Para determinar la actividad endoglucanasa se tomó $0,4 \mathrm{ml}$ del líquido libre de células diluido 10 veces y se añadió 3,5 ml de CMC al 1\% (Sigma, Medium viscosity) y $0,1 \mathrm{ml}$ de buffer acetato de sodio 1,0 M (pH 6,0). Este sistema fue incubado a $50{ }^{\circ} \mathrm{C}$ durante $30 \mathrm{~min}$. Cumplido el tiempo de incubación, se midió la liberación de azúcares reductores por el método del arsenomolibdato de Nelson (1944) y Somogyi (1952). La actividad fue expresada en unidades internacionales (UI) por $\mathrm{ml}$, considerando una unidad como la cantidad de enzima que libera un micromol de glucosa por minuto (Stutzenberger y Lupo, 1986; Ceroni y Gutiérrez-Correa, 1988; y Steiner et al., 1991).

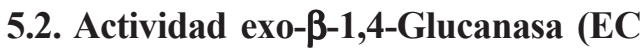
3.2.1.91) o Avicelasa. La actividad exoglucanasa fue determinada según Stutzenberger (1972) y Ceroni y Gutiérrez- 
Tabla 1. Porcentaje de muestras positivas a actinomicetos termófilos por fuentes de procedencia.

\begin{tabular}{|c|c|c|c|c|}
\hline Muestra & $\begin{array}{l}\text { Total de } \\
\text { muestras } \\
\text { procesadas }\end{array}$ & $\%$ & $\begin{array}{l}\text { N. }{ }^{\circ} \text { de } \\
\text { muestras } \\
\text { positivas }\end{array}$ & $\%$ \\
\hline Compost & 39 & 54,93 & 24 & 33,80 \\
\hline Suelos & 18 & 25,35 & 3 & 4,23 \\
\hline Estiércol & 9 & 12,67 & 1 & 1,40 \\
\hline Heno & 5 & 7,04 & 0 & 0,00 \\
\hline TOTALES & 71 & 100,00 & 28 & 39,43 \\
\hline
\end{tabular}

Correa (1988). El ensayo exoglucanasa consistió en colocar en un tubo de ensayo $50 \mathrm{mg}$ de papel filtro Whatman N. ${ }^{\circ} 1$ al cual se le añadió $0,8 \mathrm{ml}$ de buffer acetato de sodio $0,6 \mathrm{M}$ (pH 6,0) y 3,2 ml del líquido libre de células. Este sistema se incubó $50{ }^{\circ} \mathrm{C}$ durante $30 \mathrm{~min}$ y se determinó la liberación de azúcares reductores.

5.3. Actividad $\boldsymbol{\beta}-\mathbf{1 , 4 - G l u c o s i d a s a ~ ( E C ~}$ 3.2.1.21) o Celobiasa. La actividad bglucosidasa se determinó según Bernier y Stutzenberger (1989) y Ceroni (1988), utilizando para ello $1 \mathrm{ml}$ del filtrado y $1 \mathrm{ml}$ de salicina $10 \mathrm{mM}$ en buffer acetato de sodio $1 \mathrm{M}(\mathrm{pH}$ $6,0)$. Este sistema se incubó en las mismas condiciones que en los casos anteriores y se midió luego la liberación de azúcares reductores.

\section{Determinación de azúcares reductores y proteínas solubles.}

Los azúcares reductores se determinaron según Nelson (1944) y Somogyi (1952), utilizando glucosa como estándar. Las proteínas solubles fueron determinadas por el método de Lowry et al. (1951) utilizando seroalbúmina bovina fracción V (Sigma) como estándar.

\section{Determinación de biomasa celular.}

Se determinó por diferencia de pesos entre los tubos con micelio sedimentado y secado a $105{ }^{\circ} \mathrm{C}$ durante $24 \mathrm{~h}$ y los tubos vacíos secados a $100{ }^{\circ} \mathrm{C}$ durante dos horas. La biomasa fue expresada en mg de micelio por $\mathrm{ml}$.

\section{Resultados}

\section{Actinomicetos celulolíticos termófilos aislados.}

De las $71(100 \%)$ muestras procesadas entre compost, suelos, estiércol y heno, 28 resultaron positivas al aislamiento de los actinomicetos celulolíticos termófilos, que representó el 39,43\% del total (Tabla 1). De las 28 muestras positivas a estos microorganismos, 24 correspondieron al compost que significó el $33,80 \%$ del total; en tanto que las otras muestras mostraron menor positividad al aislamiento (Tabla 1).

En la Tabla 2, se presenta el número de cepas aisladas de actinomicetos termófilos por tipo de muestra, observándose que de las 304 se aislaron 255 de las muestras de compost lo que representa el $83,88 \%$ del total; mientras que de las otras muestras se aislaron en menor proporción. Asimismo, del total de actinomicetos termófilos, 158 cepas resultaron en alguna medida celulolíticas de acuerdo a los criterios cualitativos establecidos, de las cuales 131 cepas fueron aisladas a partir del compost, lo que significó el 43,10\% del total, con resultados en cifras menores que las restantes que procedieron de las otras muestras (Tabla 2).

\section{Identificación de los actinomicetos celulolíticos termófilos aislados.}

Las $158(100 \%)$ cepas de actinomicetos celulolíticos termófilos fueron identificados en géneros y/o especies conforme se indica en la

Tabla 2. Frecuencia de cepas de actinomicetos termófilos celulolíticos por fuente de procedencia (F.P.)

\begin{tabular}{lcccc}
\hline F.P. & \multicolumn{1}{c}{$\mathbf{N}^{{ }^{\circ}}$} & \multicolumn{3}{c}{$\mathbf{N}^{{ }^{\circ} \text { de cepas }}$} \\
& de cepas & $\mathbf{0}$ & celulolíticas & $\mathbf{0}$ \\
\hline Compost & 255 & 83,88 & 131 & 43,10 \\
Suelos & 37 & 12,17 & 15 & 4,93 \\
Estiércol & 12 & 3,95 & 12 & 3,95 \\
TOTAL & $\mathbf{3 0 4}$ & $\mathbf{1 0 0 , 0 0}$ & $\mathbf{1 5 8}$ & $\mathbf{5 1 , 9 8}$ \\
\hline
\end{tabular}


Tabla 3. Frecuencia de cepas de actinomicetos celulolíticos termófilos por géneros y/o especies en 28 muestras positivas de compost, suelos y estiércol.

\begin{tabular}{|c|c|c|c|c|}
\hline Género y/o especie & cepas & & & $\%$ \\
\hline Streptomyces sp. & 80 & & 50,63 & \\
\hline Thermomonospora curvata & 25 & & $15,8 \overline{2}$ & \\
\hline T. chromogena & 22 & & 13,92 & \\
\hline Thermomonospora sp. & 20 & 74 & 12,66 & 46,84 \\
\hline T. alba & 7 & & 4,43 & \\
\hline Thermomobifida fusca & 2 & & 1,27 & \\
\hline Otros Actinomicetos & 2 & & 1,27 & \\
\hline TOTAL & 158 & & 100,00 & \\
\hline
\end{tabular}

Tabla 3. Vemos que 80 correspondieron a Streptomyces sp. que representó el 50,63\% del total de cepas aisladas; en tanto que al género Thermomonospora correspondió 74 aislados que significó el 46,84\%.

Considerando las especies de Thermomonospora, las T. curvata y $T$. chromogena correspondieron a 25 y 22 cepas, equivalentes a $15,82 \%$ y $13,92 \%$, respectivamente; mientras tanto, la T. fusca y T. alba expresaron cifras muy inferiores. De otro lado, las cepas de Streptomyces sp. aisladas presentaron micelio aéreo abundante, predominando cepas con micelio de color gris claro $\mathrm{u}$ oscuro. En cuanto al número y disposición de las esporas —otra característica importante para distinguir los géneros de actinomicetoslos aislados de Streptomyces presentaron esporas en cadenas espiraladas o rectas. Igualmente expresaron un micelio vegetativo bien desarrollado. Las cepas de Thermomonospora se distinguen del género Streptomyces por presentar esporas únicas agrupadas en racimos o en forma aislada, además de la presencia de un micelio aéreo blanco como característica de la colonia, a excepción de la $T$. chromogena (datos no mostrados).

\section{Determinación cualitativa de la activi- dad celulolítica.}

Con el fin de corroborar la actividad celulolítica de las $158(100 \%)$ cepas de actinomicetos termófilos evaluadas preliminarmente según su crecimiento en Agar CzapekDox modificado, éstas se sometieron a una segunda prueba cualitativa de la actividad en los medios mínimos de Crawford y McCoy + papel filtro y el de Skinner + papel filtro, de acuerdo a los criterios ya mencionados. Se consigna este carácter en la Tabla 4, observándose que en el medio de Crawford y McCoy, 145 cepas $(91,77 \%)$, mostraron en alguna medida capacidad de degradar el papel filtro, de las cuales, 12 tuvieron muy buena actividad celulolítica (4+) que representó el $7,60 \%$ del total de cepas evaluadas. Encontramos también que 71 (44,94\%) cepas tuvie-

Tabla 4. Actividad celulolítica cualitativa de 158 cepas de actinomicetos termófilos en dos medios mínimos con papel filtro (P.F.)

\begin{tabular}{|c|c|c|c|c|c|c|c|c|}
\hline \multirow[t]{2}{*}{$\begin{array}{l}\text { Actividad } \\
\text { celulolítica* }\end{array}$} & \multicolumn{4}{|c|}{$\begin{array}{l}\text { Medio mínimo de Crawford } \\
\text { y McCoy + P.F. }\end{array}$} & \multicolumn{4}{|c|}{ Medio mínimo de Skinner + P.F } \\
\hline & cepas & & $\%$ & & cepas & & $\%$ & \\
\hline $4+$ & 12 & & 7,60 & & 4 & & $2, \overline{53}$ & \\
\hline $3+$ & 71 & 145 & 44,94 & 91.77 & 29 & 137 & 18,35 & 86.70 \\
\hline $2+$ & 50 & 145 & 31,64 & 91,17 & 54 & $13 /$ & 34,17 & 86,10 \\
\hline $1+$ & 12 & & 7,59 & & 50 & & 31,65 & \\
\hline - & $1 \overline{3}$ & & 8,23 & & 21 & & 13,30 & \\
\hline TOTAL & 158 & & 100,00 & & 158 & & 100,00 & \\
\hline
\end{tabular}

*4+, muy buena actividad celulolítica sobre papel filtro, como única fuente de carbono.

$3+$, buena actividad celulolítica.

$2+$, regular actividad celulolítica.

$1+$, escasa actividad celulolítica.

-, ausencia de actividad celulolítica. 
Tabla 5. Evaluación de las actividades enzimáticas (AE) de la endoglucanasa de 10 cepas de actinomicetos celulolíticos termófilos expresados en $\mathrm{UI} / \mathrm{ml}$, sus determinaciones específicas por proteínas (AEP) y por biomasa (AEB), a las 72 horas de producción de celulasas en cultivo sumergido.

\begin{tabular}{lccc}
\hline \multicolumn{1}{c}{ Cepa } & AE (UI/ml) & AEP (UI/mg) & AEB (UI/mg) \\
\hline Thermomonospora sp. 7CMC6 & 2,10 & 4,06 & 0,78 \\
T. curvata 7CMC8 & 2,72 & 5,54 & 0,90 \\
Streptomyces sp. 8CMC2 & 2,49 & 7,75 & 0,30 \\
Streptomyces sp. 28CMC2 & 2,20 & 4,25 & 1,18 \\
Streptomyces sp. 8CMC4 & 2,06 & 4,59 & 0,67 \\
Streptomyces sp. 7CMC10 & 2,03 & 20,14 & 0,87 \\
Streptomyces sp. 11CMC1 & 2,03 & 9,55 & 0,83 \\
Streptomyces sp. 15CC3 & 1,98 & 6,08 & 0,32 \\
Streptomyces sp. 13CMC1 & 1,81 & 2,73 & 0,13 \\
Streptomyces sp. 12CC2 & 1,01 & 5,01 & 0,34 \\
\hline
\end{tabular}

ron buena actividad celulolítica (3+), en tanto que las restantes presentaron actividades menos significativas.

Por el contrario, en el medio de Skinner + papel filtro sólo se observaron 4 cepas con muy buena actividad celulolítica (4+), lo que significó el 2,53\% y 29 cepas con buena actividad celulolítica $(3+)$, lo que representó el $18,35 \%$. Las restantes mostraron menores actividades o fueron nulas (Tabla 4).

\section{Determinación cuantitativa de la acti- vidad celulolítica}

\subsection{La actividad endo- $\boldsymbol{\beta}-\mathbf{1 , 4 - G l u c a n a s a}$} (EC 3.2.1.4) o CMCasa. De las 10 cepas seleccionadas para las determinaciones cuantitativas de la actividad endoglucanasa, las cepas de T. curvata 7CMC8 y Streptomyces sp. 8CMC2 presentaron las mayores actividades enzimáticas (AE) expresadas en Unidades Internacionales por $\mathrm{ml}$ de líquido postcultivo, correspondiendo a 2,72 y 2,49 UI/ $\mathrm{ml}$ por cepa, respectivamente (Tabla 5); mientras que las restantes mostraron actividades enzimáticas entre 2,2 y 1,011 UI/ml.

Refiriéndonos a la actividad específica por proteínas (AEP), fue el Streptomyces sp. $7 \mathrm{CMC} 10$ el que expresó 20,14 UI/mg de pro- teínas solubles, equivalente a 2,1 veces más de actividad específica por proteínas de la subsiguiente cepa, Streptomyces sp.11CMC1, con 9,55 UI/mg (Tabla 5).

Asimismo, la cepa de Streptomyces sp. 28CMC2 presentó la mayor actividad especí-

Tabla 6. Evaluación de las actividades enzimáticas (AE) de la exoglucanasa de $10 \mathrm{ce}$ pas de actinomicetos celulolíticos termófilos expresados en $\mathrm{UI} / \mathrm{ml}$ : sus determinaciones específicas por proteínas (AEP) y por biomasa (AEB), a las 72 horas de producción de celulasas en cultivo sumergido.

\begin{tabular}{lccc}
\hline \multicolumn{1}{c}{ Cepa } & AE & AEP & AEB \\
& $(\mathbf{U I} / \mathbf{m l})$ & $(\mathbf{U I} / \mathbf{m g})$ & $\mathbf{( U I / m g )}$ \\
\hline Streptomyces sp. 8CMC2 & 0,33 & 1,04 & 0,04 \\
Streptomyces sp. 8CMC4 & 0,33 & 0,73 & 0,11 \\
Streptomyces sp. 28CMC2 & 0,30 & 0,58 & 0,16 \\
Streptomyces sp. 15CC3 & 0,29 & 0,89 & 0,05 \\
Streptomyces sp. 12CC2 & 0,27 & 1,34 & 0,09 \\
Streptomyces sp. 7CMC10 & 0,27 & 2,61 & 0,11 \\
Streptomyces sp. 13CMC1 & 0,26 & 0,39 & 0,02 \\
Streptomyces sp. 11CMC1 & 0,26 & 1,22 & 0,11 \\
Thermomonospora sp. 7CMC6 & 0,26 & 0,49 & 0,10 \\
T. curvata 7CMC8 & 0,28 & 0,57 & 0,09 \\
\hline
\end{tabular}


fica por biomasa (AEB), que correspondió a $1,18 \mathrm{UI} / \mathrm{mg}$ de micelio por $\mathrm{ml}$ de cultivo, seguida por la cepa de Streptomyces sp. 7CMC10 con una AEB de 0,87 UI/mg de micelio por ml de cultivo (Tabla 5).

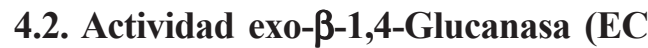
3.2.1.91) o Avicelasa. De las 10 cepas sometidas a las determinaciones de las actividades enzimáticas de exoglucanasa, la cepa de Streptomyces sp. 8CMC2 presentó mayor actividad con $0,33 \mathrm{UI} / \mathrm{ml}$, seguida muy cercanamente por las cepas de Streptomyces sp. 8 CMC4 y $28 \mathrm{CMC} 2$ con 0,33 y $0,30 \mathrm{UI} / \mathrm{ml}$, respectivamente (Tabla 6).

En cuanto a las actividades especifícas por proteínas (AEP), la cepa de Streptomyces sp. 7CMC10 presentó 2,61 UI/mg de proteínas solubles equivalente a 1,95 veces que la subsiguiente con 1,34 UI/mg (Streptomyces sp. 12CC2; Tabla 6).

En cuanto a los resultados de la actividad específica por biomasa (AEB), la cepa de Streptomyces sp. 28CMC2 expresó la máxima actividad con $0,16 \mathrm{UI} / \mathrm{mg}$ de micelio por $\mathrm{ml}$ seguida por la cepa de Streptomyces sp. 7CMC10 con $0,11 \mathrm{UI} / \mathrm{mg}$ y las cepas de Streptomyces sp. 8CMC4 y 11CMC1, igualmente con 0,11 UI/mg (Tabla 6).

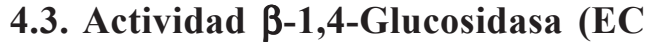
3.2.1.21) o Celobiasa. De igual modo, de las 10 cepas sometidas a determinaciones de las actividades $\beta$-glucosidasa, la cepa de Streptomyces sp. 11CMC10 presentó mayor actividad de esta enzima correspondiéndole $0,62 \mathrm{UI} / \mathrm{ml}$; muy cercanamente en rendimiento estuvo la cepa de Streptomyces sp. 7CMC10; mientras que las restantes mostraron actividades enzimáticas entre 0,42 y 0,28 $\mathrm{UI} / \mathrm{ml}$ (Tabla 7). Evaluando la cepa de Streptomyces sp. 7CMC10, vemos que ésta presentó la mayor actividad específica por proteínas (AEP) correspondiente a 5,40 UI/ mg de proteínas solubles, que significó 1,85 veces más que la subsiguiente, representada por la cepa de Streptomyces sp. 11CMC1 con $2,91 \mathrm{UI} / \mathrm{mg}$; en tanto que las restantes mos- traron sus actividades específicas en menor proporción (Tabla 7).

En cuanto a la actividad específica por biomasa (AEB), las cepas de Streptomyces sp. $11 \mathrm{CMC} 1$ y $7 \mathrm{CMC} 10$ presentaron los mayores valores siendo en cada caso 0,25 y $0,24 \mathrm{UI} / \mathrm{mg}$ de micelio por $\mathrm{ml}$, respectivamente (Tabla 7 ).

\section{Discusión}

De acuerdo a los resultados consignados en la Tabla 1, los actinomicetos termófilos predominaron en sustratos "calientes" tales como el compost, que concuerdan con los reportes de otros investigadores (Cross, 1968; Lacey y Dutkiewicz, 1976a; Cross, 1981; McCarthy y Cross, 1981; Goodfelow y Williams, 1983).

Considerándose que muchas muestras de suelos y estiércol fueron negativas al aislamiento de actinomicetos termófilos (Tabla 1), en las que idénticos resultados obtuvieron Kuo y Hartman (1966), esto nos pondría de manifiesto que estos tipos de muestras no serían los adecuados para el establecimiento de estos organismos. En lo referente a la negatividad

Tabla 7. Evaluación de las actividades enzimáticas (AE) de la $\beta$-glucosidasa $(\beta G)$ de 10 cepas de actinomicetos celulolíticos termófilos expresados en $\mathrm{UI} / \mathrm{ml}$ : sus determinaciones específicas por proteínas (AEP) y biomasa (AEB), a las 72 horas de producción de celulasas en cultivo sumergido.

\begin{tabular}{lccc}
\hline Cepa & AE & AEP & AEB \\
& (UI/ml) & (UI/mg) & (UI/mg) \\
\hline Streptomyces sp. 11CMC1 & 0,62 & 2,91 & 0,25 \\
Streptomyces sp. 7CMC10 & 0,55 & 5,40 & 0,24 \\
Streptomyces sp. 12CC2 & 0,42 & 2,06 & 0,14 \\
Thermomonospora sp. 7CMC6 & 0,41 & 0,79 & 0,15 \\
T. curvata 7CMC8 & 0,28 & 0,57 & 0,09 \\
Streptomyces sp. 13CMC1 & 0,40 & 0,60 & 0,03 \\
Streptomyces sp. 15CC3 & 0,39 & 1,20 & 0,06 \\
Streptomyces sp. 8CMC2 & 0,33 & 1,04 & 0,04 \\
Streptomyces sp. 8CMC4 & 0,33 & 0,73 & 0,11 \\
Streptomyces sp. 28CMC2 & 0,30 & 0,58 & 0,16 \\
\hline
\end{tabular}


de cepas de actinomicetos a partir de heno, otros investigadores, por el contrario, reportan muy buenos resultados de estos organismos, sobre el mismo sustrato (Cross, 1968; Lacey y Dutkiewicz, 1976a y 1976b).

Respecto de la biodiversidad de la flora actinomicetal celulolítica termófila, el género Streptomyces se aisló predominantemente, seguido de varias especies del género Thermomonospora (Tabla 3). Estos hallazgos concuerdan con los reportados por Crawford y McCoy (1972) y Strom (1985a y 1985b), de muestras de suelos y compost, respectivamente. En 1984a McCarthy y Cross hallan un predominio de $T$. fusca respecto de $T$. chromogena y $T$. curvata y otras especies en diversas muestras; en nuestro caso, las especies $T$. chromogena y T. curvata se hallaron en mayor proporción, y queda aún un porcentaje apreciable de cepas que no se ubica en los patrones taxonómicos descritos hasta la fecha.

No logramos aislar otros actinomicetos monospóricos diferentes de los géneros Thermomonospora y Thermobifida, como es el caso del género Thermoactinomyces también muy ubicuo en suelos, sedimentos, aguas $\mathrm{y}$ en material en descomposición como el compost. Se reconoce en la actualidad que su rol en la naturaleza es distinto ya que este género no es celulolítico (McCarthy y Cross, 1984a y 1984b; Lacey y Cross, 1989).

Refiriéndonos a la actividad celulolítica cualitativa de nuestros aislados (Tabla 4), en la que 145 cepas expresaron esta actividad en alguna medida, obtuvieron idénticos resultados Stutzenberger et al. (1970). No obstante estas apreciaciones, los métodos de selección de las mejores cepas celulolíticas de actinomicetos de máximo rendimiento no han sido todavía reportados, de tal manera que éstas se puedan correlacionar con las determinaciones cuantitativas.

Tansey (1971) utilizó celulosa ablandada con ácido ortofosfórico para evaluar semicuantitativamente hongos celulolíticos termófilos; igualmente, Jhonson et al. (1982) utilizaron también celulosa ablandada, celulosa microcristalina y celulosa amorfa para evaluar cepas celulolíticas de $C$. thermocellum. Se ha demostrado que actividades elevadas de endoglucanasas se correlacionan con la formación de un gran halo de hidrólisis de la celulosa ablandada (Ceroni y Gutiérrez-Correa, 1988). Es importante por lo tanto, estandarizar un método aplicable a los actinomicetos celulolíticos que nos permita correlacionar el tamaño de los halos de hidrólisis con la actividad enzimática correspondiente. Sin embargo, la degradación del papel filtro es un método alternativo, que permitió, por ejemplo a Ramasamy et al. (1981) seleccionar cepas celulolíticas de Pseudomonas a partir de lodos.

Por otro lado, la inducción del sistema enzimático de la hidrólisis de la celulosa requiere de los sustratos adecuados en los medios de cultivo a probar; en nuestro caso el medio mínimo de Crawford y McCoy (1972) más papel de filtro nos permitió una adecuada selección de las mejores cepas celulolíticas de actinomicetos termófilos, en comparación con el medio mínimo de Skinner (1960). Las pruebas en medios mínimos, además, nos permitieron determinar las condiciones apropiadas de cultivo de los actinomicetos para la producción de celulasas. El medio para la producción de estas enzimas (Crawford y McCoy + CMC 1\%, lactosa 1\% y Tween 80 0,2\%), adoptado por nosotros para las pruebas cuantitativas de las actividades enzimáticas, resultó ventajoso (Tablas 5, 6 y 7). Resultados menos significativos fueron obtenidos por Crawford y McCoy (1972), pero sin utilizar lactosa y Tween 80; la lactosa conjuntamente con la CMC probablemente permite una adecuada expresión de las enzimas, coadyuvada por el Tween 80 , un surfactante no iónico, que estimula la liberación de las celulasas al medio extracelular. Resultados similares fueron obtenidos por Stutzenberger (1987) evaluando la estimulación específica de la secreción de celulasas por una cepa de T. curvata; igualmente, Ceroni y Gutiérrez-Correa (1988) ha- 
llaron significativos niveles de celulasas extracelulares en hongos silvestres aislados de nuestro medio.

En cuanto a las actividades específicas por proteínas (AEP), éstas constituyen una medida de la pureza de una enzima. En consecuencia, la importancia de contar con cepas con elevadas actividades específicas resulta de mucha importancia; es interesante que en nuestro estudio las cepas de Streptomyces sp. 7CMC10 y 11CMC1 mostraron los mayores valores con $20.14 \mathrm{UI} / \mathrm{mg}$ y $9.55 \mathrm{UI} / \mathrm{mg}$ de proteínas referentes a endoglucanasas, respectivamente. Del mismo modo, la actividad específica por proteínas para la exoglucanasa quedó demostrada en la cepa de Streptomyces sp. 7CMC10 (2,61 UI/mg); sin embargo, similares valores fueron hallados por Stutzenberger (1972) evaluando una cepa de T. curvata y también por Crawford y McCoy (1972) en cepas de T. fusca y $S$. thermodiastaticus.

Nuestras cepas también respondieron significativamente a las cuantificaciones de la $\beta$-glucosidasa extracelular (Tabla 7). La presencia de ésta evita la inhibición de las otras 2 enzimas; su acción enzimática, por tanto, es ventajosa, si la comparamos con la producción de esta enzima en niveles bajos por los

Tabla 8. Determinación de la biomasa celular de 10 actinomicetos celulolíticos termófilos a las $72 \mathrm{~h}$ de producción de celulasas en cultivo sumergido.

\begin{tabular}{ll}
\hline Cepa & Biomasa celular $(\mathrm{mg} / \mathrm{ml})$ \\
\hline Streptomyces sp. 13CMC1 & 14,32 \\
Streptomyces sp. 7CMC6 & 2,71 \\
Streptomyces sp. 28CMC2 & 1,87 \\
Thermomonospora curvata 7CMC8 & 3,01 \\
Streptomyces sp. 8CMC4 & 3,07 \\
Streptomyces sp. 15CC3 & 6,20 \\
Streptomyces sp. 8CMC2 & 8,38 \\
Streptomyces sp. 11CMC1 & 2,44 \\
Streptomyces sp. 12CC2 & 2,97 \\
Streptomyces sp. 7CMC10 & 2,34 \\
\hline
\end{tabular}

hongos celulolíticos más estudiados (Ceroni y Gutiérrez-Correa, 1988). En nuestro estudio, nuevamente vemos que la cepa de Streptomyces sp. 7CMC10 tuvo rendimiento significativo de $\beta$-glucosidasa (5,40 UI/mg). Bernier y Stutzenberger (1988) reportaron que la $\beta$-glucosidasa extracelular tiene una mayor afinidad con la celobiosa y con los glucósidos $p$-nitrofenilos, mientras que en nuestro caso lo tuvieron hacia la salicina.

La actividad específica por biomasa (AEB) es otro de los parámetros que debe considerarse en la selección de cepas celulolíticas, porque nos relaciona la producción enzimática en función de la biomasa y a la vez, nos permite saber si la cepa de actinomiceto crece bien o escasamente al utilizar un sustrato celulósico, nutriente útil para seleccionar cepas en la producción de biomasa con fines alimenticios. Evaluando las cepas en función de la AEB, vemos que las cepas de Streptomyces sp. 28CMC2 y $T$. curvata 7CMC8 mostraron los mayores valores de actividad endoglucanasa $(1,18$ y $0,90 \mathrm{UI} / \mathrm{mg}$ de micelio/ml) (Tabla 5), lo que nos muestra las ventajas de estas cepas en el rendimiento enzimático fundamentado.

Por otro lado, analizando las cepas en función de la producción de biomasa, los Streptomyces sp. 13CMC1 y 8CMC2 que presentaron 14,32 y $8,38 \mathrm{mg} / \mathrm{ml}$ de medio de cultivo (Tabla 8), lo que nos está indicando buenos niveles de producción de masa celular por $\mathrm{ml}$ de medio, cifras significativas si las comparamos con las reportadas por Ceroni y Gutiérrez-Correa (1988), quienes refirieron valores mucho menores en hongos mesófilos celulolíticos.

\section{Agradecimientos}

Al CONCYTEC por el financiamiento parcial de la presente investigación.

\section{Literatura citada}

Bernier, R. y F. Stutzenberger. 1989. Stabilization of Thermomonospora curvata b-glucosidase by a low molecular weight intracellular factor. Lett. Appl. Microbiol. 8: 9-13. 
Ceroni, A. 1988. Detección y evaluación de germoplasma celulolítico en 136 cepas de hongos de suelo. Tesis: Biólogo. Facultad de Ciencias. Universidad Nacional Agraria. Lima, Perú.

Ceroni, A. y M. Gutiérrez-Correa. 1988. Producción de celulasas por hongos: estudios cinéticos en hongos silvestres. Boletín de Lima 55: 13-20.

Crawford, D. L. y E. McCoy. 1972. Cellulases of Thermomonospora fusca and Streptomyces thermodiastaticus. Appl. Microbiol. 24: 150152.

Crawford, D. L. 1975. Cultural, morphological, and physiological characteristics of Thermomonospora fusca (strain $190 \mathrm{Th}$ ). Canadian J. Microbiol. 21: 1842-1848.

Cross, T. 1968. Thermophilic actinomycetes. J. Appl. Bacteriol. 31: 36-53.

Cross, T. 1981. The monosporic actinomycetes, pp 2091-2102. En Starr, M. P., Stolp, H., Trüper, H.G., Balows, A. y Schlegel, H. G. (ed.) The Prokaryotes a Handbook on habitats, isolation and identification of bacteria. Springer-Verlag Berlin Heidelberger. New York, USA.

Cross, T. 1989. Growth and examination of actinomycetes. Some guidelines, pp. 23402343. En: William, S. T., Sharpe, M. E. y Holt, J. G. (ed.), Bergey Manual of systematic bacteriology, vol. 4. Williams y Wilkins, Baltimore, USA.

Goodfelow, M. y S. T. Williams. 1983. Ecology of actinomycetes. Ann. Rev. Microbiol. 37: 189216.

Gutiérrez-Correa, M. 1988. Producción de etanol a partir de materiales celulósicos. Primera Jornada de Avance en Biotecnología. UNI. Lima, Perú. pp. 31.

Johnson, E. C.; M. Sakajoh, G. Halliwell, A. Madia y A. L. Demain. 1982. Saccharification of complex cellulosic substrates by the cellulase system from Clostridium thermocellus. Appl. Environ. Microbiol. 43: 1125-1132.

Kuo, M. J. y P. A. Hartman. 1966. Isolation of amylolytic strains of Thermoactinomyces vulgaris and production of thermophylic actinomycete amylases. J. Bacteriol. 92: 723-726.

Lacey, J. y J. Dutkiewicz. 1976a. Methods for examining the microflora of mouldy hay. J. Appl. Bacteriol. 41: 13-27.

Lacey, J. y J. Dutkiewicz. 1976b. Isolation of actinomycetes and fungi from mouldy hay using a sedimentation chamber. J. Appl. Bacteriol. 41:315-319.

Lacey, J. y T. Cross. 1989. Genus Thermoactinomyces. En Williams, S. T., Sharpe, M. E. y Holt, J. G. (ed.), Bergey's Manual of Systematic Bacteriology, vol. 4. Williams y Wilkins. Baltimore, USA. pp. 2574-2585.
Lowry, O. H., N. J. Rosenbrought, A. L. Farr y R. J. Randall. 1951. Protein measurement with folin phenol reagent. J. Biol. Chem. 193: 265-275.

Lynd, L. R.; P. J. Weimer, W. H. van Zyl y I. S. Pretorius. 2002. Microbial cellulose utilization: fundamentals and biotechnology. Microb. Mol. Biol. Rev. 66 :506-577.

McCarthy, A. J. y T. Cross. 1981. A note on a selective isolation medium for the thermophilic actinomycete Thermomonospora chromogena. J. Appl. Bacteriol. 51: 299-302.

McCarthy, A.J. y T. Cross. 1984a. A taxonomy study of Thermomonospora and other monosporic actinomytes. J. Gen. Microbiol. 130: 5-25.

McCarthy, A. J. y T. Cross. 1984b. Taxonomy of Thermomonospora and related oligosporic actinomycetes. En: Biological, biochemical and biomedical aspects of actinomycetes. Academic Press Inc. pp. 521-536.

Morales, M. y R. Masson. 1988. El compost y su preparación. En: J. Vega (ed.), Manual Práctico de huerto biológico. Ediciones Chirre. Lima, Perú. pp. 31-36.

Murashima, K.; A. Kosugi y R. H. Doi. 2002. Synergistic effects on crystalline cellulose degradation between cellulosomal cellulases from Clostridium cellulovorans. J. Bacteriol. 184: 5088-5095.

Nelson, N. 1944. A photometric adaptation of Somogyi method for the determination of glucose. J. Biol. Chem. 153: 375-380.

Ramasamy, K.; M. Meyers; J. Bevers y H. Verachtert. 1981. Isolation and characterization of cellulolytic bacteria from activated sludge. J. Appl. Bacteriol. 51: 475-481.

Skinner, F. A. 1960. The isolation of anaerobic cellulosedescomposing bacteria from soil. J. Gen. Microbiol. 22: 539-554.

Somogyi, M. 1952. Note on sugar determination. J. Biol. Chem. 195: 19-23.

Steiner, J.; C. Socha y J. Eyzaguirre. 1991. Mejoramiento de la producción de celulasas por una cepa nativa de Penicillium purpurogenum. XI Congreso Latinoamericano de Microbiología, VI Congreso Argentino de Microbiología. Buenos Aires, Argentina. Resúmenes, pp. E 69.

Strom, P.F. 1985a. Effect of temperature on bacterial species diversity in thermophilic solid-waste composting. Appl. Environ. Microbiol. 50: 899-905.

Strom, P. F. 1985b. Identification of thermophilic bacteria in solid-waste composting. Appl. Environ. Microbiol. 50: 906-913.

Stutzenberger, F. y D. Lupo. 1986. pH-dependent thermal activation of endo-1,4-b-glucanasa in Thermomonospora curvata. Enzyme and Microbial Technology 8: 205-208. 
Stutzenberger, F.J. 1972. Cellulolytic activity of Thermomonospora curvata: nutricional requirements for cellulase production. Applied Microbiology 24: 77-82.

Stutzenberger, F. J. 1987. Component-specific stimulation of cellulase secretion in Thermomonospora curvata by the surfactant Tween 80. J. Appl. Bacteriol. 63: 239-244.

Stutzenberger, F. J.; A. J. Kaufman y R. D. Lossin.1970. Cellulolytic activity in municipal solid waste composting. Canadian Journal of Microbiology 16: 553-560.

Tansey, M. R. 1971. Agar diffusion assay cellulolitic ability thermophilic fungi. Archiv Microbiology 77: 1-11.
Walter, S. y H. Schrempf. 1996. Physiological studies of cellulase (Avicelase) synthesis in Streptomyces reticuli. Appl. Environ. Microbiol. 62: 10651069.

Zeikus, J. G.; A. Ben-bassat; T. K. Ng; R. J. Lamed. 1981. Thermophilic ethanol fermentations. En: Hollander, A., R. Rabson; R. Pietro y Wolfe. (Ed.). Trends in the biology of fermentations for fuels and chemicals. Plenum Publishing Corp. New York, USA. pp. 441-461. 